\title{
O mercado de camelôs e as contribuições ao desenvolvimento local de uma cidade
}

The market for barkers and contributions to local development of a city

Les vendeurs du marché et contribuent au développement local d'une ville

\section{Los vendedores callejeros y las contribuciones al desarrollo local de una ciudad}

\author{
Luciano Mendes* \\ (mendes@usp.br) \\ Neusa Rolita Cavedon** \\ (neusa.cavedon@ufrgs.br)
}

Recebido em 24/10/2013; revisado e aprovado em 29/01/2014; aceito em 13/02/2014

\begin{abstract}
Resumo: o objetivo neste artigo é o de evidenciar as implicações do mercado de camelôs no desenvolvimento local da cidade de Três Lagoas, MS, com vistas a trazer elementos que relativizem o olhar sobre o trabalho dos camelôs. A pesquisa realizada se caracteriza como pesquisa qualitativa. Os resultados mostram que o mercado de camelô na região é de suma importância, tanto na oferta de produtos não encontrados no mercado formal, como na possibilidade de integração de um número de indivíduos ao mercado de trabalho.

Palavras-chave: Mercado camelô. Desenvolvimento local. Cidade.

Abstract: The objective of this article is to highlight the implications of the market peddlers in local development of the city of Três Lagoas, MS, in order to bring elements that relativized the look on the work of street vendors. The research is characterized as qualitative research techniques. The results show that the market barker in the region is of paramount importance, both in the supply of products not found in the formal market, such as the possibility of integrating a number of individuals to the labor market.

Key words: Market peddlers. Local development. City.

Résumé: L'objectif de cet article est de mettre en évidence les implications des colporteurs de marché, le développement local de la ville de Três Lagoas, MS, afin d'apporter des éléments qui relativisées le regard sur le travail des colporteurs. La recherche se caractérise par des techniques de recherche qualitatives. Les résultats montrent que le colporteur de marché dans la région est d'une importance capitale, tant dans la fourniture de produits ne figurant pas dans le marché formel, comme la possibilité d'intégrer un certain nombre de personnes sur le marché du travail. Mots-clés: Colporteurs de marché. Développement local. Ville.

Resumen: El objetivo de este artículo es destacar las implicaciones de los vendedores del mercado, el desarrollo local de la ciudad de Três Lagoas, MS, con el fin de aportar elementos que relativizan la mirada en el trabajo de los vendedores ambulantes. La investigación se caracteriza por técnicas cualitativas de investigación. Los resultados muestran que el vendedor de mercado en la región es de suma importancia, tanto en el suministro de productos que no se encuentran en el mercado formal, como la posibilidad de integrar a un número de personas al mercado de trabajo.

Palabras clave: Vendedores del mercado. Desarrollo local. Ciudad.
\end{abstract}

\section{Introdução}

O comércio popular costuma ser percebido de maneira negativa dentro do contexto urbano. Todavia, nem sempre, essa ótica se mostra como sendo verdadeira, posto que o comércio popular pode suprir lacunas existentes seja em relação à gama diversificada de produtos a serem oferecidos, seja em razão de a oferta de mercadorias ocorrer a preços mais acessíveis a determinadas camadas da população. Desconsiderar esses aspectos é olhar de maneira absoluta e estigmatizante para um comércio que, a despeito de qualquer crítica, vem se mantendo e atendendo a demanda da população, em especial, nas cidades cuja afluência de determinados produtos ainda se mostra ausente ou insuficiente para suprir as necessidades dos cidadãos.

Duas vertentes nessa visão sobre a atividade de camelô devem ser salientadas, ao observar os papéis exercidos por esses sujeitos no desenvolvimento local. Uma vertente é a integração de um grupo de pessoas, muitas vezes constituído de excluídos ou marginalizados, aos processos econômicos. A possibilidade de obter renda através da economia informal tem sido uma das únicas possibilidades a uma gama de indivíduos e contribuído para o aumento nas condições de vida deste segmento da população. Uma outra vertente, mais vinculada à atuação desse

\footnotetext{
* Universidade de São Paulo (USP/ESALQ), São Paulo, SP, Brasil.

** Universidade Federal do Rio Grande do Sul (UFRGS/EA), Porto Alegre, RS, Brasil.
} 
grupo, é de possibilitar a oferta diversificada de produtos no mercado local. Produtos esses que, muitas vezes, não são encontrados no mercado formal local. Tendo em vista que a possibilidade de consumo de uma população é um dos fatores de manutenção desse grupo em uma localidade, exercer esse papel de ofertante de produtos diversos ao mercado configura-se como algo relevante.

É com essa abordagem que o presente artigo busca tratar das questões que envolvem o desenvolvimento local. A partir de diferentes abordagens teóricas, o objetivo neste artigo é o de evidenciar as implicações do mercado de camelôs no desenvolvimento local da cidade de Três Lagoas, MS, com vistas a trazer elementos que relativizem o olhar sobre o trabalho dos camelôs. Para atingir esse objetivo, a técnica de pesquisa utilizada foi a entrevista semiestruturada, a partir de uma pesquisa de cunho qualitativo, descritivo. Antes de abordar essa questão metodológica, foi necessária uma discussão mais abrangente sobre o conceito de desenvolvimento local. Nos próximos itens esse universo (teórico/ empírico) será descortinado.

\section{O conceito de desenvolvimento local}

O conceito de desenvolvimento local, da forma como surge a partir da década de 1990, possui suas principais características atreladas à ideia de desenvolvimento econômico (como uma crítica a esse modelo de desenvolvimento), que tinha sido alvo das discussões sobre desenvolvimento e subdesenvolvimento dos países capitalistas, assim como das ideias sobre centro e periferia nos processos econômicos (FURTADO, 2007). O ponto fulcral em que se baseavam as teorizações (sobre o desenvolvimento econômico), antes da década de 1990, estava assentado sobre a modernização, as tecnologias desenvolvidas e a estrutura industrial existente nos países, implicando a classificação dos países em desenvolvidos, e aqueles qualificados como subdesenvolvidos (GOULART, 2006).

Não é possível negar que o conceito de desenvolvimento local nos dias atuais, apesar das metamorfoses existentes no próprio conceito de desenvolvimento (desenvolvimento sustentado, desenvolvimento sustentável, desenvolvimento integrado, desenvolvimento regional, etc.), não escapou aos ditames econômicos. O que ocorreu foi a integração de outros aspectos para que houvesse a qualificação necessária ao termo desenvolvimento local, como o fato de inserir nessas discussões os atributos sociais, ambientais e culturais (MARTINS, 2002; SENRA, 2010).

O termo desenvolvimento local surgiu como a possibilidade ou mesmo contraponto em relação a todo aparato teórico que se tinha sobre o desenvolvimento econômico, que passou a ser visto como crescimento econômico. A intenção era - no entremeio a todo processo de descentralização da administração pública, da impossibilidade dos Estados conduzirem, de forma geral, os processos de desenvolvimento e das restrições evidentes nos modelos de desenvolvimento econômico - de possibilitar a localização de formas peculiares de desenvolvimento. Essas formas peculiares de desenvolvimento, observadas no nível local, pressupunham as capacidades que os grupos sociais tinham de obter a sustentação econômica, social e ambiental de suas práticas (PIRES; MÜLLER; VERDI, 2006).

Fischer (2002a) salienta que o "local" está ligado a duas ideias que conduzem à ambiguidade: uma referente à inércia, e outra, ao movimento. Em um sentido estrito, salienta essa autora, o "local" surge como um espaço delimitado, com características estáticas; e, também, numa relação direta com o global, o que instaura mudanças constantes nas relações estabelecidas entre os atores. Assim, o localismo nas discussões sobre desenvolvimento permitia uma crítica aos processos evolutivos e também à comprovação de heterogeneidade nas constatações sobre o que seria desenvolvimento. Fischer (2002a) relata que a polissemia existente sobre o tema desenvolvimento local estava direcionada, principalmente, em relação à heterogeneidade, que conduzia os estudiosos a apropriações diversas sobre o termo desenvolvimento local.

$\mathrm{Na}$ análise desenvolvida por Barbosa e Mioto (2007), fica claro que essa metamorfose conceitual está diretamente ligada ao fato do desenvolvimento local ser uma "prática sem teoria". Esses autores procuram elucidar que as vertentes sobre o significado de desenvolvimento local passam por uma gama de fatos empíricos, que conduzem a apropriações diversas, sem que isso incorra - mesmo que o 
autor tenha uma visão teórica que subjaz a sua análise - em construções teórico-conceituais. Por esse motivo, as concepções de desenvolvimento voltadas para o "local" surgem através de três instâncias, conforme salientou Fischer (2002a), que são: poder enquanto relações de força; o conceito de espaço delimitado e formação de identidade; e, práticas específicas. Essas três instâncias é que mostram a possibilidade de ênfase no local, em face da diversidade de manifestações e relações em espaços sociais compartilhados.

O conceito de desenvolvimento local aparece também "travestido" pelos pressupostos ideológicos de várias instituições. Como mostra Almeida (2010), o Ministério do Desenvolvimento Social e Combate à Fome vincula desenvolvimento local à segurança alimentar; a Organização das Nações Unidas (ONU) constitui o desenvolvimento local a partir do Índice de Desenvolvimento Humano Municipal (IDH-M), procurando substituir os índices mais economicistas, a exemplo do Produto Interno Bruto (PIB) per capita; o SEBRAE atrela as discussões sobre o desenvolvimento local à integração de diversos setores produtivos, formados pelo estímulo e fortalecimento das micro e pequenas empresas; e o SENAC analisa o desenvolvimento local a partir de estratégias da comunidade em utilizar seus recursos e potencialidades para o desenvolvimento das pessoas e das comunidades.

Apesar dessa polissemia conceitual, alguns fatores perpassam as discussões de vários autores sobre o que vem a ser desenvolvimento local. Primeiro, uma preocupação com o social, em argumentações que evidenciam a necessidade de inclusão social, diminuição das desigualdades, ampliação do acesso a bens e serviços (públicos e privados), redução da pobreza, entre outros (COELHO, 2004; MULS, 2008; SENRA, 2010). Segundo, a integração da dimensão ambiental, em que a intenção é diminuir os impactos ambientais e os desperdícios, assim como gerar proteções e conservações dos recursos naturais (SANTOS JUNIOR, 2001; SACHS, 2004). Terceiro, é a preocupação com as micro e pequenas empresas e com o potencial que emana das comunidades (MARTINELLI; JOYAL, 2004; LUCAS, 2006).

Assim, fica evidente nessa breve retrospectiva teórica sobre desenvolvimento local, a necessidade de fortalecimento dos empreendimentos ou ações desenvolvidas em determinadas comunidades (ou cidades) como fator significativo em termos de preocupação acerca do desenvolvimento local. Ainda nesse contexto, como essa diversidade de práticas não torna o "local", em suas dimensões internas, homogêneo, fica evidente que o desenvolvimento local é produzido por atores diversos e práticas múltiplas, que deem sustentação ao processo de melhoria econômica, de diminuição na desigualdade social, de aumento na qualidade de vida e de acesso a bens e serviços. Seria ilusório pensar que todas essas vertentes fossem implantadas e conduzidas por estruturas únicas, como os governos locais. São os atores nesse processo que permitem contribuições diversas em cada etapa e com propósitos diferenciados, mas integrados ao desenvolvimento local.

Por esse motivo, ao elucidar aspectos ligados ao desenvolvimento local, alguns autores, como Oliveira (2001), Senhora e Takeuchi (2005) e Almeida (2010), salientam que, além dos aspectos econômicos, ainda existe um processo de articulação social que visa a: inserção de todos os segmentos sociais a novas dinâmicas econômicas e política-culturais; geração e consolidação das iniciativas empreendedoras locais; harmonização e regulação das relações entre cidadão, comunidade e empresa em seu contexto socioambiental; e construção da sustentabilidade econômica das atividades locais. Na visão de Fischer (2002a), não há como falar de desenvolvimento local sem referência a conceitos como pobreza, miséria, exclusão, participação, solidariedade, produção e competitividade.

Dessas articulações, outros autores têm enfatizado a importância e o fortalecimento das micro e pequenas empresas (MARTINELLI; JOYAL, 2004), do empoderamento das organizações locais e do poder local (FISCHER, 2002b) e do surgimento e efetivação do capital social (BAQUERO; CREMONESE, 2008; MULS, 2008). No que tange ao fortalecimento das micro e pequenas empresas, as discussões sobre redes de empresas (MARTINELLI; JOYAL, 2004; MARTINS, 2002) e arranjos produtivos locais (COELHO, 2004; REIS, 1988) tomam a cena na promoção do desenvolvimento local. Muito dessas iniciativas surgem à margem do Estado e sem 
incentivos, consolidando-se antes mesmo de tornarem-se objeto de atenção por parte do poder público local.

Ainda, as discussões sobre o empoderamento das organizações e do surgimento do poder local estão atreladas ao fortalecimento dos atores locais, no que tange às interferências nas ações desenvolvidas pelo poder público, assim como na condução e efetivação das potencialidades existentes na comunidade local (FISCHER, 2002b; ALBAGLI, 2006; LUCAS, 2006).

A teoria sobre o capital social, discutida inicialmente por Putnam (2000), considera aspectos como: o grau de confiança existente entre os atores sociais, as normas de comportamento cívico praticadas e o nível de associatividade característico. Para o referido autor, o capital social (as redes, as normas e a confiança) facilita a coordenação e cooperação em vista de benefícios mútuos em determinadas comunidades. O que fica nítido nessas aproximações, por exemplo, entre desenvolvimento local e capital social ou poder local, é sempre a possibilidade aberta de que os atores locais possam desenvolver estratégias que possibilitem aumento na qualidade de vida, diminuição das desigualdades sociais na região ou na comunidade, acesso a bens e serviços, diminuição nos níveis de pobreza, entre outras soluções.

\section{Método}

Esta pesquisa se caracteriza como sendo de cunho qualitativo, descritiva. A pesquisa qualitativa visa responder a questões do tipo "como" ou "por quê" os eventos ou fenômenos ocorrem (BERG, 2006). É uma pesquisa que se preocupa com a profundidade e amplitude das informações e menos com a contagem das opiniões e de respostas pré-elaboradas pelo pesquisador (NEUMAN, 2007). Além disso, procura compreender os eventos ou fenômenos a partir do ponto de vista dos sujeitos envolvidos, deixando que os sujeitos possam construir seus significados dentre os elementos que eles dominam (FLICK, 2009).

A utilização da pesquisa descritiva tem a intenção de isentar o pesquisador de maiores inferências sobre as informações obtidas (LAKATOS; MARCONI, 2002). Não no sentido de ser "neutro" na descrição do pro- cesso, mas no sentido de não ter a obrigação de explicar as relações causais dos eventos ou de ter a obrigação de encontrar respostas prontas e acabadas no desenvolvimento da pesquisa (BAUER; GASKELL; ALLUM, 2002). A pesquisa descritiva, integrada à pesquisa qualitativa, é utilizada neste artigo a partir da ideia de "construção social da realidade" (BERGER; LUCKMANN, 1985), o que mostra que as ações, os papéis e as visões estão sempre em modificação, são dinâmicas, não permitindo conclusões ou constatações imutáveis, cristalizadas (SILVERMAN, 2010).

Como técnicas na pesquisa qualitativa foram realizadas entrevistas semiestruturadas. As entrevistas, como salientam Fontana e Frey (2000), incluem ampla variedade de formas e também uma multiplicidade de usos. A entrevista semiestruturada, salientam esses autores, é formada por questões préestabelecidas ou roteiros de entrevista, mas não de categorias de respostas prontas, objetivas, ficando em aberto para o entrevistado a resposta a ser considerada. Como salienta Minayo (1996, p. 121), "quando se trata de apreender sistemas de valores, de normas, de representações de determinado grupo social, ou quando se trata de compreender relações, o questionário se revela insuficiente".

Por esse motivo, para uma apreensão das práticas e dos papéis realizados pelos camelôs na cidade de Três Lagoas, MS, houve a necessidade de conduzir entrevistas com três camelôs, denominados ficticiamente no decorrer deste trabalho de: Camelô1, Camelô2 e Camelô3. Além desses, ainda foram feitas entrevistas com três clientes assíduos do mercado de camelôs, sendo denominados: Cliente1, Cliente2 e Cliente3. No que tange ao representante da prefeitura, foi realizada entrevista com o antigo Secretário da Indústria e Comércio, que participou ativamente, durante 6 anos, de todo processo de transferência dos camelôs e da constituição do mercado camelô na cidade de Três Lagoas, denominado: Secretário1.

As entrevistas foram analisadas a partir da análise de conteúdo qualitativa (MAYRING, 2000). Essa forma de análise visa obter uma perspectiva mais qualitativa do corpus de entrevista, diferente da análise de conteúdo tradicional, em que costuma haver a contagem e atribuições entre os elementos 
que compõem o texto. Mayring (2000) salienta que existem três formas de se realizar a análise de conteúdo qualitativa. A primeira é a "sumarização", na qual a intenção é reduzir o material de tal maneira que restem apenas os conteúdos essenciais. A segunda é a "explicação", que possui como objetivo de integrar materiais adicionais para a melhor compreensão, esclarecimento e interpretação do corpus em estudo. A terceira é a "estruturação", que se realiza através do recorte no corpus ou material escolhido, tendo em vista critérios preestabelecidos.

Como os conteúdos essenciais das entrevistas estão ligados aos papéis dos camelôs no processo de desenvolvimento local da cidade de Três Lagoas, então a forma de análise de conteúdo qualitativa foi a sumarização. Dito isso, o próximo passo será o de apresentar os resultados e discussão sobre as informações geradas no âmbito da pesquisa.

\section{Sobre a cidade em estudo}

A cidade de Três Lagoas está localizada no extremo leste do Estado de Mato Grosso do Sul. Tal região foi habitada e desbravada, inicialmente, por bandeirantes paulistas, em reconhecimento do território nacional, assim como pela busca de novas áreas destinadas à pecuária extensiva. Após esse processo de desbravamento inicial dessa região, ocorreu a construção da estrada de ferro Noroeste do Brasil (NOB), com o objetivo de escoar produtos do Centro-Oeste brasileiro para as região mais povoadas do Sudeste e do Sul. Para a construção dessa estrada de ferro, foi erguido um acampamento de engenheiros e, logo em seguida, um novo povoado surgia naquele lugar. A partir desse povoado, em 1914, foi criada a vila de Três Lagoas, que obteve emancipação política e territorial em 1916 (QUEIROZ, 2004).

Os primeiros ambulantes surgiram, na cidade, junto com a constituição do primeiro povoado, impulsionados pelas necessidades de alimentos e bebidas naquela região. Outra parte era produzida e gerada na própria região, através de uma agricultura destinada à subsistência. Com a constituição da cidade, os primeiros comércios se instalaram na região central, dada a demanda que surgia na cidade. Assim, o mercado ambulante sempre esteve efetivo e foi parte da lógica de desenvolvimento de muitas cidades, e no caso de Três Lagoas não foi diferente (CORREA, 1999).

O mercado de camelôs, especificamente, instalou-se na região central da cidade em meados da década de 1990, oferecendo produtos contrabandeados do Paraguai. Nessa época, ainda se misturavam os ambulantes e os camelôs, com a prerrogativa de que os últimos possuíam ponto fixo em várias calçadas da cidade. Alguns dos camelôs que surgiram na mesma época eram provenientes de outras regiões do país, muitos trabalhavam como ambulantes e resolveram se instalar na cidade. Com essas primeiras manifestações é que algumas pessoas já residentes na cidade resolveram também se inserir nesse mercado, por conta do desemprego e de um número significativo de pessoas que se aposentavam pela Estrada de Ferro Noroeste do Brasil (NOB).

A atração e instalação do mercado de camelôs na cidade ligam-se diretamente ao processo de industrialização que começou a ocorrer no município. Em meados da década de 1990, tendo em vista o potencial logístico e posicionamento estratégico da cidade de Três Lagoas, isso fez com que o Prefeito e o Secretário da Indústria e Comércio fossem buscar investimentos na expansão industrial do município. Dados os incentivos fiscais concedidos pelo Governo do Mato Grosso do Sul, junto com as iniciativas e incentivos da própria prefeitura de Três Lagoas, em 1997 iniciou-se o processo de industrialização do município, com a atração de empresas diversificadas (MARTIN, 2000).

$\mathrm{O}$ crescimento industrial da cidade revela-se pelo número de habitantes e pela geração de empregos. Em 1990, a cidade tinha 65.748 habitantes. Em 2000, após as primeiras iniciativas de industrialização, a cidade passou a acolher 85.886 habitantes. Em 2013, a cidade possuía 105.224 habitantes. Em períodos médios de 10 anos, a cidade agregou cerca de 20.000 habitantes. Em 2013, passou a ser a terceira cidade com maior número populacional do Estado do Mato Grosso do Sul, perdendo apenas para a capital, Campo Grande, com 805.397 habitantes, e para Dourados, com 200.729 habitantes (IBGE, 2013).

Com relação à geração de empregos, em 2004, o sistema industrial instalado na cidade gerava cerca de 2.500 mil empregos diretos. 
Após 2006 e até 2013, a cidade vem atingindo os maiores índices de novos empregos no Estado do Mato Grosso do Sul. Nos três últimos anos, tem despontado em primeiro lugar na geração de empregos. Dados do Governo do Estado mostram que no último trimestre de 2013, Três Lagoas gerou 790 novas vagas de empregos, enquanto Dourados, segunda maior cidade do Estado, gerou 486 novas vagas de empregos. A capital, Campo Grande, ficou em quinto lugar, com apenas 199 novas vagas (CAGED, 2013).

Apesar de todo esse potencial, o crescimento da cidade e da industrialização ocorreu em um curto espaço de tempo, pouco mais de 15 anos. Nesse período, a população da cidade quase dobrou, e a estrutura urbana não conseguiu acompanhar todo esse crescimento. Apesar de o mercado formal de emprego estar em amplo crescimento no município, o que tem atraído um contingente populacional significativo, em termos de mercado de abastecimento geral de produtos destinados às famílias, não houve um crescimento capaz de acompanhar aquele iniciado com o processo de industrialização. Diante desse déficit no comércio é que os camelôs passaram a ser atores-chaves, no sentido de abastecer as famílias que passaram a residir na cidade, de produtos não encontrados no mercado local. Esse assunto será discutido no próximo tópico.

\section{O mercado de camelôs na cidade de Três Lagoas, MS}

Ao ter contato com a história do mercado camelôs de Três Lagoas, contada pelos camelôs e pelos sujeitos que, no início das atividades naquela cidade, estabeleciam algum tipo de relação com os camelôs (como é o caso do antigo Secretário da Indústria e Comércio), ficou evidente que as atitudes dos camelôs, naquela época, tinham sido mais ativas, no processo de venda dos produtos. Os camelôs realizavam um assédio constante sobre os possíveis consumidores que transitavam próximos às barracas instaladas nas calças em frente aos bancos e às lojas de varejo existentes no centro da cidade.

Na época nós precisávamos resolver o problema dos camelôs no centro da cidade, porque a cidade estava suja, feia e você não conseguia andar pelas calçadas. Porque, além deles [os camelôs] ocuparem as calçadas, tinha o assédio que eles faziam nas pessoas. Então você estava andando e o pessoal puxando você para dentro das barracas. (Secretário1).

Nesse trecho da entrevista, fica evidente que a atitude dos camelôs que ocupavam a área central da cidade era totalmente diferente daquela que eles possuem hoje. Isso porque nos dias atuais todo esse assédio não ocorre mais, as pessoas que transitam próximo ao mercado de camelôs não são importunadas. Há possibilidade de várias explicações para isso, mas a que mais se tornou evidente foi a da centralidade desse mercado no contexto da cidade de Três Lagoas.

Na mesma linha salientada pelo entrevistado (Secretário1), também os camelôs entrevistados tocavam no assunto de maneira semelhante. Esses camelôs diziam que assediavam os consumidores naquela época, pois era uma forma de vender.

Como a gente estava incomodando no centro, nas portas dos comerciantes, eles viram que estávamos incomodando e mandaram a gente para cá. Mas lá era bom, porque cada um tinha um ponto certo também. Tirávamos a barraca no final do dia, mas cada um tinha seu ponto e montava a barraca no mesmo lugar. Como era mais no centro, a gente tinha um número grande de clientes. Conquistávamos os clientes na porta do banco. Não tinha um que não comprava de mim... (risos)... Era uma briga para conquistar os clientes. Depois era só vê-lo e ir logo perguntando se não estava precisando de algo. Eu sabia o nome de cada cliente meu. Tinha uma agendinha, assim, que eu anotava tudo... (risos) ...Anotava até quem comprava mais... (risos)... Era muito bom! (Camelô1).

Esse fato pode ser interpretado ao ter-se presente a situação econômica e social em que as pessoas viviam, naquela época, na cidade de Três Lagoas, ou seja, justamente em um período anterior ao processo de industrialização. Após esse período, os camelôs foram retirados das calçadas que ocupavam no centro e transferidos para outro local, também próximo ao centro, onde foram mais bem acomodados. Nesse novo local, a prefeitura organizou toda a estrutura de instalação para que o mercado de camelôs ficasse fixo naquele local, sendo proibidos de se instalarem 
novamente nas calçadas do centro da cidade. Essa transferência, que ocorreu no início do ano 2000, impactou significativamente - pelo menos inicialmente - as vendas dos camelôs.

Quando a gente veio para cá não tinha nada. Era um paradeiro e a gente veio da rua, né? A gente ficava na frente do banco. A gente já pegava o cliente na frente do banco... (risos)... Aí a gente veio para cá e uns três meses, assim, não passava ninguém aqui...Aí depois o pessoal começou a vir e hoje aqui é um ponto turístico da cidade. Aqui não tem quem não venha. A gente tem cliente das classes $\mathrm{A}$ até a E. De todas as categorias. O rico, o pobre e o médio. Vêm todos comprar nos camelôs...E a gente tem clientes da alta sociedade... (risos)... (Camelô2).

A ênfase dada nesse trecho da entrevista de que um número significativo de pessoas da cidade consome produtos do mercado de camelôs, mostra que este não é um mercado marginalizado - particularmente na cidade de Três Lagoas - em relação ou em comparação ao mercado de varejo formal. Esse mercado de camelôs, até pela ampla capacidade de abastecimento da demanda local por produtos diversos, possui uma centralidade interessante, pois grande parte dos produtos de consumo das famílias é abastecida por esse mercado.

Não foram raras as vezes em que os próprios camelôs diziam que ali era um lugar onde se vendia de tudo. Um dos entrevistados, que também é um dos mais antigos camelôs presente naquele lugar, com mais de 20 anos de profissão, salientou que:

Por mim, eu passo o resto da minha vida aqui. Aqui a gente vende bem. A gente já tem a clientela. Aqui pelo menos a gente sabe que a gente vende. [...] Mas você sabe que eu acho que onde o camelô estiver o povo vai atrás...vai! vai!... Aqui no camelô você acha de tudo... desde uma agulha a um... tudo que você pensar aqui no camelô tem (Camelô3).

Esse frase - "aqui no camelô você acha de tudo" - não representava somente um jargão, mas uma realidade. A quantidade de produtos comercializados naquele local é grande, e vai desde bancos e almofadas para sofás, passando por malas e artefatos para pesca, até ervas e produtos naturais. Isso para mostrar somente as coisas mais exóticas que eram comercializadas naquele local. Não há restrições. Existem produtos para piscinas, roupas variadas, tênis e sapatos, eletroeletrônicos, computadores, perfumes, vídeo games e jogos, televisores e antenas e também componentes variados.

Devido ao fato de a cidade não possuir um comércio amplamente estruturado, o mercado de camelôs supre em muito as necessidades ali existentes. Por mais que a primeira impressão fosse de que esse mercado era marginalizado, com uma série de pessoas em condições econômicas desfavoráveis, ou que era um mercado que concorria com o comércio vendendo produtos de baixa qualidade a um preço mais acessível, muito disso foi sendo descontruído.

Em relação ao mercado de varejo formal, os camelôs possuem produtos exclusivos, que são encontrados somente ali. Nas três entrevistas com os clientes do mercado camelô, em todas elas, essas questões sobre a exclusividade de produtos que os camelôs tinham, ficaram evidentes. Isso pode ser visto nos fragmentos abaixo.

Tem produto que só se encontra lá nos camelôs. Você já nem procura, vai direto ao camelódromo. Não, e eu faço questão de ir nas lojas. Esses dias quebrou o transformador do meu telefone sem fio. Eu passei em todas as lojas de eletroeletrônicos. Em todas as lojas! Sabe o que aconteceu? Todas elas me indicaram o camelódromo! Entendeu? E logo vão dizendo que somente os camelôs que tem e que você só vai encontrar lá. Se você quiser comprar numa loja regulariza$\mathrm{da}$, vai ter que ir em outra cidade comprar, porque aqui só tem nos camelôs (Cliente1).

Manutenção de eletrodoméstico. Liquidificador. Geladeira. Processador antigo. Você precisa da borrachinha do processador, você vai lá e encontra. Só ali que tem. Você precisa de um copo para o liquidificador que quebrou, só ali que tem. No comércio daqui você não encontra. $E$ vou te dizer mais, eles nem fazem força para ter. Não sei se são produtos que dão menos lucro, mas nem precisa gastar combustível e procurar no comércio. Tem que ir direto nos camelôs (Cliente2).

Camisa de clube, por exemplo. Camisa de clube, se você for comprar original é um absurdo. Não dá para comprar. Daí você vai lá no camelódromo que tem e você nem nota muito a diferença. Você ainda no comércio aqui não encontra muitas camisas. Lá você encontra de tudo quanto é time. Aqui nas 
lojas você encontra só de alguns times. Lá não, você encontra de tudo (Cliente3).

Essas entrevistas mostram que muitos dos produtos consumidos na cidade de Três Lagoas são provenientes, em exclusividade, do mercado camelô. Com isso, fica fácil concluir a importância e centralidade desse mercado como sustentáculo no consumo das famílias que lá residem. Provavelmente, os custos familiares na cidade de Três Lagoas seriam altos se não houvesse o mercado de camelôs, pois muitos produtos seriam adquiridos em outras localidades. Mas não é somente isso, é uma questão também de fixação das famílias e dos empregados na cidade, pois sendo deficitário o mercado de varejo local, muitas famílias poderiam ter como opção residir em outros municípios. Isso geraria um impacto negativo no processo de industrialização e na absorção de mão de obra qualificada. Essa centralidade e essa demanda em relação aos produtos comercializados nesse mercado estão diretamente vinculadas a esse processo de industrialização. Com o intuito de compreender essa dinâmica na cidade em estudo, no próximo tópico será discutido o papel do mercado camelô no desenvolvimento local da cidade de Três Lagoas, MS.

\section{Desenvolvimento local e o papel exercido pelo mercado camelô}

A aproximação entre as discussões sobre o desenvolvimento local com o caso dos camelôs de Três Lagoas não foi ao acaso. Primeiro foi a verificação de o mercado possibilitar a integração de um contingente de pessoas à economia. Segundo foi a constatação da centralidade desse mercado no município. Essa centralidade ocorre de diversas formas, mas a principal é a capacidade de abastecimento de uma série de produtos que não são encontrados no comércio local. Estando integrado ao comércio local, o mercado de camelôs supre o município de vários produtos, tanto de necessidades mais básicas quanto de produtos supérfluos. O fato é que o mercado de camelôs de Três Lagoas, MS não atende somente o consumidor final, mas atende também outros comerciantes que utilizam insumos adquiridos através dos camelôs. Como exemplo, muitos produtos são consumidos por pequenas empresas de serviços que realizam consertos em eletrodomésticos/eletrônicos.

Essa centralidade do mercado é que torna evidente sua contribuição no desenvolvimento local, que se expressa através do abastecimento de produtos essenciais ou não para uma comunidade que vivencia amplo processo de industrialização; assim como contribui para a manutenção de insumos necessários à prestação de serviços realizados por pequenas empresas da região; e também gera emprego e renda para uma parcela da população municipal que não integra o mercado de emprego formal. Além disso, o camelódromo possibilita, através dos baixos preços, que um número significativo da população municipal tenha a possibilidade de consumo.

Como bem expôs Miller (2007), as teorias sobre o consumo enfatizam, em grande parte, os fatores negativos, deixando à margem implicações reais de que o consumo possui seu significado atrelado à cultura material, que permite acesso e que produz relações sociais e formas de sociabilidade. Apesar de o consumo, na forma como é realizado nos dias atuais, ter suas expressões mais evidentes no sistema capitalista, como salientou Barbosa (2004), a visão discutida por Miller (2007) sobre a materialidade cultural do consumo procura enfatizar que este (o consumo) sempre esteve na base das sociedades humanas.

O trabalho de Miller (2007) mostra que existem formas regionalizadas de consumo, que estão além ou aquém do consumo enquanto atendendo a necessidades básicas ou enquanto manifestação de um fetichismo publicitário. Que ambas as coisas podem [ou mesmo] possuem sua parcela de influência neste processo, o que Miller (2007) procura destacar é que o consumo em si não se reduz apenas a uma dessas vertentes, transfigurando-se ou mesmo alterando seu significado em grupos sociais diferenciados ou comunidades.

Ao estudar o mercado de camelô na cidade de Três Lagoas, MS é visível, numa rápida apreensão, que o consumo dos produtos está diretamente influenciado por um fetichismo publicitário ou mesmo que grande parte dos produtos consumidos é destinada ao atendimento de necessidades básicas. Apesar de não ser possível negar todas essas influências no processo de consumo, ainda existem formas de sociabilidade e de 
relações pessoais as quais desmistificam alguns atributos negativos que fazem parte das representações sociais desse mercado. Especificamente no caso de Três Lagoas, os clientes salientaram questões relacionadas à qualidade dos produtos, à cordialidade dos camelôs, ao pronto atendimento, entre outras.

Mesmo que à margem da legalidade $\mathrm{e}$ da formalidade, o comércio de camelôs tem contribuído com a disseminação de uma série de produtos que, com maior ou menor importância, vem possibilitando um nível significativo de consumo, assim como o acesso de um número de pessoas a produtos que antes não lhes era viável obter. Problemas relacionados à legalidade e à formalidade estão em todos os segmentos econômicos. No mercado de camelôs, de forma geral, esses problemas são mais evidentes, dada uma série de outros problemas (por exemplo a não existência, no passado, de um lei endereçada ao microempreendedor individual ou mesmo a falta de informações claras sobre a abertura de uma empresa), que não somente o de um grupo social oportunista tentando obter maiores lucros através do comércio informal ou ilegal.

Dito isso, na tentativa de suprir ou mesmo diminuir o hiato econômico e social existente na região de Três Lagoas, MS, empreendimentos como o mercado de camelôs foram de importância central na possibilidade de acesso das pessoas que se instalavam naquela região a uma diversidade de produtos que não era encontrada no comércio local. O processo de industrialização que passou a ocorrer na cidade de Três Lagoas, MS nos últimos anos, criou um hiato no abastecimento de produtos no mercado local que foi, gradativamente, suprido pelo mercado de camelôs. Esse papel no abastecimento é evidente no caso dos camelôs dessa cidade, o que tem contribuído com o desenvolvimento local da região. Nas discussões sobre o desenvolvimento local, estão expressas peculiaridades locais (FISCHER, 2002a), diversidades de ações e atores (ALMEIDA, 2010), ênfase nas atitudes ou práticas micro (BARBOSA; MIOTO, 2010), entre outras, que contribuem para o desenvolvimento de uma localidade ou região (SENRA, 2010).

As limitações na atuação e no papel exercido pelo mercado de camelôs são evidentes apenas no que tange às questões voltadas à sustentabilidade, à proteção e à preservação do meio ambiente. Isso porque esse mercado possibilita o empoderamento da comunidade local (FISCHER, 2002b), através da integração de um contingente de pessoas ao mercado de trabalho e à economia (mesmo que informal), assim como o consumo de produtos diversos (mesmo que alguns provenientes de um fetichismo publicitário) e que, em termos de valores, são adequados ao poder aquisitivo da população municipal. Com isso, esse mercado contribui também para a promoção da justiça social (MULS, 2008) e redução da pobreza (FISCHER, 2002a), como já salientado, através de uma opção em termos de trabalho para as pessoas "excluídas" ou "marginalizadas" do mercado formal (aposentados, analfabetos ou com baixa escolaridade).

Sendo a ideia de que o desenvolvimento local é realizado por vários atores e de forma heterogênea (SENHORA; TAKEUCHI, 2005; ALBAGLI, 2006), o mercado de camelôs se constitui como mais um ator nesse processo e, por isso, não é de se esperar que eles [os camelôs] deem conta de todas as ações regionais que possibilitem a variedade de atributos que congregam o conceito de desenvolvimento local.

Além disso, no caso específico da cidade de Três Lagoas, MS - e também de muitas outras cidades brasileiras -, o processo de desenvolvimento econômico e social não ocorreu de forma amplamente estruturada, no sentido de que, para o surgimento de um parque industrial, eram necessários determinados pré-requisitos ou estruturas que, efetivamente, possibilitassem o desenvolvimento sustentado das iniciativas que seriam constituídas.

É visível na história econômica brasileira (FURTADO, 2007) uma série de empreendimentos conduzidos, muitas vezes pelo poder público, os quais dispunham do mínimo [ou nem isso] capaz de constituir um crescimento inicial em determinadas áreas [o modelo de substituição de importações é um exemplo nítido dessa afirmação - para saber mais sobre esse modelo ver Furtado (2007)] e que depois permitiu o desenvolvimento e sustentação das atividades.

Três Lagoas, MS não foi exceção a essa regra, pois a preocupação do poder público no início do processo de constituição de um 
parque industrial na cidade - conforme entrevista realizada com o Secretário1 - era com a instalação das empresas na região, sem preocupação evidente em termos de estruturas econômicas e sociais capazes de dar suporte a toda mudança [econômica, ambiental e social] que, ao serem conduzidas, produziriam na cidade.

Por esse motivo, houve um ajustamento constante dos sujeitos integrantes a esse processo para suprir e conceder o mínimo de recursos necessários à comunidade existente na região. Os camelôs existentes ali cumpriram parte desse papel, na tentativa de abastecer o mercado local com produtos que antes não eram encontrados, ao mesmo tempo em que o exercício desse papel era algo convidativo a uma parcela da população local que observava uma oportunidade de emprego e renda.

Assim, por mais que aspectos como ilegalidade e informalidade sejam evidentes no contexto da atividade de camelô, o que tem impulsionado o poder público local à formalização e à legalização dessa atividade, esses atores [os camelôs], particularmente naquela localidade, foram e são de suma importância para o desenvolvimento local. $\mathrm{O}$ que ficou visível também no caso dos camelôs de Três Lagoas foi todo um movimento do poder público local e do SEBRAE (Serviço Brasileiro de Apoio às Micro e Pequenas Empresas) para formalizar e legalizar, assim como profissionalizar a categoria de camelô. Tal ação busca atingir o fortalecimento das micro e pequenas empresas na localidade visando configurar atuações centrais para o desenvolvimento local (MARTINELLI; JOYAL, 2004).

Esses são ganhos interessantes que o camelódromo acabou ocasionando na região e que, de uma forma ou outra, impactam, direta ou indiretamente, em alguns pressupostos impulsionados no contexto do desenvolvimento local, como, por exemplo, a diminuição das desigualdades em termos de consumo e a possibilidade de aumento no poder aquisitivo através dos menores preços praticados. Mesmo que muitos dos produtos oferecidos pelos camelôs sejam falsificados ou replicados (estimulados por um fetichismo publicitário) de produtos consumidos por uma elite, muitos outros produtos atendem necessidades básicas [sabonetes, shampoos, alimentos enlatados, biscoitos, entre outros] e domésticas [artefatos em geral de cama, mesa e banho] da população existente na região. Para finalizar esse percurso, vale salientar algumas considerações finais.

\section{Considerações finais}

O objetivo neste artigo foi o de evidenciar as implicações do mercado de camelôs no desenvolvimento local da cidade de Três Lagoas, MS, com vistas a trazer elementos que relativizem o olhar sobre o trabalho dos camelôs. Assim, o fortalecimento dos empreendimentos ou ações desenvolvidas em determinadas comunidades (ou cidades) constitui um dos principais vetores para a análise do desenvolvimento local.

Ainda nesse contexto, como essa diversidade de práticas não torna o "local" homogêneo, em suas dimensões internas, fica evidente que o desenvolvimento local é produzido por atores diversos e práticas múltiplas, que buscam dar sustentação ao processo de melhoria econômica, de diminuição na desigualdade social, de aumento na qualidade de vida e de acesso a bens e serviços.

Foi dessa constatação que ficou evidente, para além dos problemas elucidados sobre a atividade de camelô de Três Lagoas (problemas de ilegalidade e informalidade), a contribuição desse mercado para o desenvolvimento local, em especial por dois fatores. $\mathrm{O}$ primeiro ligado ao processo de crescimento industrial efetivado na cidade, no qual os camelôs supriam produtos que não eram comercializados ou que o comércio local não dispunha ou tinha interesse em vender. $\mathrm{O}$ segundo, decorrente dessa centralidade do mercado na cidade, foi a possibilidade de integrar um contingente de pessoas que estavam "excluídas" ou "à margem" dos processos econômicos, tornando o próprio mercado uma possibilidade importante de emprego e renda na cidade de Três Lagoas, MS.

É nesse sentido que o mercado de camelô contribui para o desenvolvimento local da cidade de Três Lagoas. Isso devido ao fato de que a cidade passou, nos últimos anos, por um intenso processo de industrialização, na tentativa de ser a cidade com a maior concentração de indústrias na área de papel e celulose. Por esse motivo, houve a atração 
de mão de obra, o que dobrou a população da cidade. Isso tornou o mercado de consumo de bens e serviços deficitário. Foi neste panorama de deficiências que os camelôs passaram a atender a algumas das necessidades dessa população em crescimento.

\section{Referências}

ALBAGLI, S. Conhecimento, inclusão social e desenvolvimento local. Inclusão Social, Brasília, v. 1, n. 2, p. 14-22, abr./set. 2006.

ALMEIDA, F. A. Desenvolvimento local: fundamentos para uma crítica marxista. Dissertação (Mestrado em Serviço Social) - Pontifícia Universidade Católica de São Paulo, São Paulo, 2010.

BAQUERO, M.; CREMONESE, D. Desenvolvimento regional, democracia local e capital social. Ijuí, RS: Unijuí, 2008.

BARBOSA, L. Sociedade de consumo. Rio de Janeiro: Jorge Zahar, 2004.

BARBOSA, R. K.; MIOTO, B. O Desenvolvimento Local em perspectiva: explorando alguns ângulos do debate. In: SEMANA DE ENSINO E PESQUISA DA UNIVERSIDADE FEDERAL DE SANTA CATARINA, 6., 16 a 19 de Maio de 2007. Anais... Santa Catarina, 2007.

BAUER, M. W.; GASKELL, G.; ALLUM, N. C. Qualidade, quantidade e interesses do conhecimento: evitando confusões. In: GASKELL, G.; BAUER, M. W. Pesquisa qualitativa com texto, imagem e som: um manual prático. 3. ed. Petrópolis, RJ: Vozes, 2002.

BERG, B. L. Qualitative research methods for the social sciences. Boston: Pearson, 2006.

BERGER, P. L.; LUCKMANN, T. A construção social da realidade. Petrópolis: Vozes, 1985.

CADASTRO GERAL DE EMPREGADOS E DESEMPREGOS - CAGED. Sintese do mercado de trabalho formal no Mato Grosso do Sul, 2013. Disponível em: <http:// portal.mte.gov.br/data/files/8A7C812D3DCADFC30 13E141AE9CA4E5A/MS\%20março\%2013.pdf>. Acesso em: 24 abr. 2013

COELHO, F. D. Ambiência produtiva e construção social no território: o programa de desenvolvimento local no município de Piraí. In: CONGRESO INTERNACIONAL DEL CLAD SOBRE REFORMA DEL ESTADO Y DE LA ADMINISTRACION PÚBLICA, 9., Madrid, Espanha, 2-5 nov. 2004. Anais... Madrid, 2004.

CORREA, V. B. Fronteira oeste. Campo Grande, MS: UFMS, 1999.

FISCHER, T. Poderes locais, desenvolvimento e gestão: introdução a uma agenda. In: FISCHER, T. (Org.). Gestão do desenvolvimento e poderes locais: marcos teóricos e avaliação. Salvador: Casa da Qualidade, 2002a.

. A gestão do desenvolvimento local: agenda em aberto e proposta de qualificação. In: CONGRESO INTERNACIONAL DEL CLAD SOBRE REFORMA DEL ESTADO Y DE LA ADMINISTRACION PÚBLICA, 7., Lisboa, Portugal, 8-11 out. 2002. Anais... Lisboa, 2002b.
FLICK, U. Qualidade na pesquisa qualitativa. Porto Alegre: Artmed, 2009.

FONTANA, A.; FREY, J. H. The interview: from structured questions to negotiated text. In: DENZIN, N. K.; LINCOLN, Y.S. (Ed.). The Handbook of qualitative research. 2. ed. Thousand Oaks-California: Sage Publications, 2000.

FURTADO, C. Formação econômica do Brasil. São Paulo: Companhia das Letras, 2007.

GOULART, S. Uma abordagem ao desenvolvimento local inspirada em Celso Furtado e Milton Santos. Cadernos EBAPE.BR, Rio de Janeiro, v. 4, n. 3, p. 1-15, out. 2006.

INSTITUTO BRASILEIRO DE GEOGRAFIA E ESTATÍSTICA - IBGE. IBGE cidades: Três Lagoas/MS, 2013. Disponível em: <http://www.ibge.gov.br/cidadesat/painel/ painel.php?codmun=500830 . Acesso em: 20 abr. 2013.

LAKATOS, E. M.; MARCONI, M. A. Técnicas de Pesquisa. 5. ed. São Paulo: Atlas, 2002.

LUCAS, L. P. V. QualiCidades: poder local e qualidade na Administração Pública. Rio de Janeiro: Qualimark, 2006.

MARTIN, J. H. História de Três Lagoas. Bauru: Do autor, 2000.

MARTINELLI, D. P.; JOYAL, A. Desenvolvimento local e o papel das pequenas e médias empresas. Barueri, SP: Manole, 2004.

MARTINS, S. R. O. Desenvolvimento local: questões conceituais e metodológica. Interações - Revista Internacional de Desenvolvimento Local, Campo Grande, MS, v. 3, n. 5, p. 51-59, set. 2002.

MAYRING, P. Qualitative Inhaltsanalyse. In: FORUM QUALITATIVE SOZIALFORSCHUNG/FORUM: Qualitative Social Research, 2000.

MILLER, D. Consumo como cultura material. Horizontes Antropológicos, Por Alegre, ano 13, n. 28, p. 33-63, jul./ dez. 2007.

MINAYO, M. C. S. O desafio do conhecimento: pesquisa qualitativa em saúde. São Paulo: HUCITEC/ABRASCO, 1996.

MULS, L. M. Desenvolvimento local, espaço e território: o conceito de capital social e a importância da formação de redes entre organizações e instituições locais. Revista Economia, Brasília, v. 9, n. 1, p. 1-21, jan./abr. 2008.

NEUMAN, W. L. Basics of social research: qualitative and quantitative approaches. Boston: Pearson, 2007.

OLIVEIRA, F. Aproximações do enigma: o que quer dizer desenvolvimento local? São Paulo: Pólis, 2001.

PIRES, E. L. S.; MÜLLER, G.; VERDI, A. R. Instituições, território e desenvolvimento local: delineamento preliminar dos aspectos teóricos e morfológicos. Geografia, Rio Claro, SP, v. 31, n. 3, p. 437-456, set./dez. 2006.

PUTNAM, R. Comunidade e democracia: a experiência da Itália moderna. Rio de Janeiro: FGV, 2000.

QUEIROZ, P. R. C. Uma ferrovia entre dois mundos: a E. F. Noroeste Paulista na primeira metade do século XX. Campo Grande, MS: UFMS, 2004.

REIS, J. Território e sistemas produtivos locais: uma reflexão sobre as economias locais. Revista Crítica de Ciências Sociais, Coimbra, n. 12, v. 26, p. 1-15, 1988. 
SACHS, I. Desenvolvimento: includente, sustentável e sustentado. Rio de' Janeiro: Gramond, 2004.

SANTOS JUNIOR, O. A. Democracia e governo local. Rio de Janeiro: Revan, 2001.

SENHORA, E. M.; TAKEUCHI, K. P. A gestão pública entre a competição e a solidariedade: desvendando as estratégias do desenvolvimento local. In: SIMPÓSIO
DE EXCELÊNCIA EM GESTÃO E TECNOLOGIA, 2., 2005. Resende, RJ. Anais... Resende, 2005.

SENRA, K. V. Política e instituições para o desenvolvimento econômico territorial: o caso do Brasil. Santiago, Chile: CEPAL, 2010.

SILVERMAN, D. Um livro bom, pequeno e acessível sobre pesquisa qualitativa. Porto Alegre: Bookman, 2010. 